\title{
Variations in Tsou Numeral Expressions: Multipliers, Exponents, and Related Issues
}

\author{
GUJING LIN \\ Tzu-Chi University
}

\section{$1 \quad$ Introduction}

The present study investigates numeral expressions in Tsou, focusing on how lower cardinals combine with the two arithmetic strategies of addition and multiplication for composing higher cardinals. The investigation shows that in serial counting, two sets of lower cardinals collaborate for deriving higher cardinals up to the thousands on a decimal basis. The pattern of collaboration works in a way that one set of numerals (set A) marks numbers under ten as well as the hundreds $\left(x^{*} 100\right)$, and the other set (set B) is employed for the tens $\left(x^{*} 10\right)$ and the thousands $\left(\mathrm{x}^{*} 1000\right)$. I argue that the use of the two sets of lower cardinals is regulated in relation to the different exponentiations of the base 10 .

This paper is structured as follows. Section 2.1 summarizes previous studies on the principles for constructing higher numerals. Section 2.2 presents a brief overview of numerals in Formosan and other Austronesian languages, based on the studies by Blust (2009), Zeitoun, Teng, and Ferrell (2010), and Li (2006). Section 3 deals with the patterns for composing higher numerals in Tsou, with a special focus on how the two sets of lower cardinals display a typologically unusual pattern in which the expression of the multiplier registers the exponentiation of the numeral base (10 in the case of Tsou). Section 4 is the conclusion.

\section{$2 \quad$ Literature Review}

\subsection{Numeral Systems: Regularities and Variations}

Interest in numeral systems rarely fades away from the scholastic circle. Scholars with various theoretical persuasions devote a remarkable amount of attention to the principles for designating number values in languages (Schmidt 1926, Heine 1997, Comrie 2008, to name three). Despite the diverse theoretical leanings of 
Variations in Tsou Numeral Expressions

individual researchers, a near consensus emerges that higher numerals, if relevant in the surveyed language, are typically constructed according to the pattern in which some lower numeral $\mathbf{x}$ multiplied by a base $\mathbf{n}$ plus some other numeral $\mathbf{y}$ (Comrie 2008). Use of subtraction for constructing numerals is also attested, but its occurrence is significantly limited.

Even though the ideal for designating number values is for the above-mentioned $\mathbf{x n}+\mathbf{y}$ formula to be consistently served by the same set of numerals, as illustrated by the Mandarin example (1) below, various departures from the ideal have been reported.

(1) Mandarin

san bai san shi san

three hundred three ten three "333 (=3*100+3*10+3)"

Of the various departures, a frequently attested type occurs when two (or more) bases serve the $\mathbf{x n}+\mathbf{y}$ pattern, creating seemingly irregular variations among the otherwise regular series. Heine (1997:26) reports that Breton has "17" and "19" expressed by a decimal base with addition $(17=10+7 ; 19=10+9)$, but the number value " 18 " is instead constructed on a senary base $(18=3 * 6)$. Comrie (2008) reports the hybrid decimal-vigesimal system of Basque in which the numbers up to 99 are expressed using a base of 20 , whereas the hundreds are constructed with a base of 10 (i.e., the number value 256 is expressed by the pattern $\left.x^{*} 100+y * 20+z\right)$. In both Breton and Basque, variations in numeral expressions stem from the existence of two (or more) bases.

(2) Basque (Comrie 2008)

berr-eun eta berr-ogei-ta-hama-sei

two-hundred and Two-twenty-and-ten-six " $256 "(=2 * 100+2 * 20+16)$

\subsection{Numerals in the Formosan Languages}

Number values in the Formosan languages are predominately designated using the decimal system (Li 2006, Zeitoun, Teng, and Ferrell 2010). A similar preference for the decimal system is also observed among other Austronesian languages (Blust 2009). Li (2006) surveys 14 Formosan languages and reports a prevailing use of the decimal system. Of the 14 surveyed languages, Pazih is the only language displaying abundant features of a quinary system, as illustrated in (3). Unlike the pattern in Pazih, numerals in most of the other Formosan languages display features of a decimal system, as illustrated by the data from Amis in (4) 


\section{Gujing Lin}

below. ${ }^{1}$

(3) Pazih (Li 2006:139, 148-150)

$\begin{array}{ll}\text { ida } & \text { "1" } \\ \text { dusa } & \text { "2" } \\ \text { turu } & \text { "3" } \\ \text { supat } & \text { "4" } \\ \text { xasep } & \text { "5" } \\ \text { xaseb-uza } & \text { "6 }(=5+1) " \\ \text { xaseb-i-dusa } & " 7(=5+2) " \\ \text { xaseb-i-turu } & " 8(=5+3) " \\ \text { xaseb-i-supat } & \text { " } 9(=5+4) "\end{array}$

(4) Amis (Li 2006:139)

$\begin{array}{ll}\text { cəcay } & \text { "1" } \\ \text { tosa? } & \text { "2" } \\ \text { tolo? } & \text { "3" } \\ \text { səpat } & \text { "4" } \\ \text { lima? } & \text { "5" } \\ \text { Pənəm } & \text { "6" } \\ \text { pito? } & \text { "7" } \\ \text { falo? } & \text { "6" } \\ \text { siwa? } & \text { "9" } \\ \text { mo?təp; poloq } & \text { "10" }\end{array}$

Aside from being predominately decimal-based, numerals in Formosan languages also demonstrate a human/non-human dichotomy (Li 2006). Example (5) below illustrate the numerals for counting human referents in Amis, which derive from the non-human numerals in (4) via Ca-reduplication. ${ }^{2}$

\footnotetext{
${ }^{1}$ Amid the general preference for the decimal system, Li notes that the expressions for the number values " 6 " and " 8 " have been modified in languages located in northern Taiwan. The expression for " 6 " in Thao, for instance, is constructed as ka-turu " $2 * 3$ " ( $k a$ "2 times"; turu "three"). The expression for " 8 " in Amis, to take another example, is expressed using the base of 4. Li concludes that Formosan numerals are predominately decimal-based; variations exist only to a limited scale. Such a predominance of the decimal system is also seen in Blust's (2009) description of numerals in the Austronesian languages in general.

${ }^{2} \mathrm{Li}$ (2006:135) notes that human numerals in Formosan languages may derive from non-human numerals by Ca-reduplication (as found in Atayal, Seediq, Kanakanavu, Saaroa, Bunun, Thao, Amis, and Siraya), prefixation (as found in Rukai, Paiwan, Puyuma, and Kavalan), or by suppletion (as found in Tsou and Kavalan for the numeral "one").
} 
Variations in Tsou Numeral Expressions

(5) Amis human numerals (Li 2006:139)

$\begin{array}{ll}\text { ca-cəcay } & \text { "1" } \\ \text { ta-tosa? } & \text { "2" } \\ \text { ta-tolo? } & \text { "3" } \\ \text { sa-səpat } & \text { "4" } \\ \text { la-lima? } & \text { "5" } \\ \text { Pa-Pənəm } & \text { "6" } \\ \text { pa-pito? } & \text { "7" } \\ \text { fa-falo? } & \text { "6" } \\ \text { sa-siwa? } & \text { "9" } \\ \text { ma-mo?təp } & \text { " } 10 "\end{array}$

Li concludes that the human/non-human distinction is a shared feature among the Formosan languages and can be reconstructed for Proto-Austronesian (PAn). Blust (2009) holds a similar view, proposing to reconstruct two sets of numerals for Proto-Austronesian, one for counting non-human referents, the other for human referents.

Zeitoun, Teng, and Ferrell (2010) further Li's and Blust's research but propose an alternative analysis regarding numerals in the Formosan languages. While Zeitoun and her colleagues in general concur with the proposal to erect the human/non-human distinction for numerals, they argue that more attention should be directed toward the use of two sets of numerals for designating values under 10 and the tens, respectively. ${ }^{3}$ The two sets are named "free numerals" and "bound numerals" by the morphological status of their component members. Of the two sets, free numerals are employed for designating number values under 10 and bound numerals are for the multiples of ten $(20,30 \ldots 90)$, as shown by the Puyuma data in (6) below.

(6) Nanwang Puyuma (Zeitoun, Teng, and Ferrell 2010:868)

$\begin{array}{llll}\text { sa } & 1 & \text { pulru' } & 10 \\ \text { drua } & 2 & \text { maka-betra'an } & 20 \\ \text { telru } & 3 & \text { maka-telru-n } & 30 \\ \text { pat } & 4 & \text { maka-pet-el } & 40 \\ \text { lrima } & 5 & \text { maka-luwatr } & 50 \\ \text { enem } & 6 & \text { maka-nem-en } & 60 \\ \text { pitu } & 7 & \text { maka-pitu } & 70 \\ \text { walru } & 8 & \text { maka-walru } & 80 \\ \text { iwa } & 9 & \text { maka-iwa } & 90\end{array}$

\footnotetext{
3 The distinction is found in Mantauran Rukai, Isbukun Bunun, Mayrinax Atayal, Truku Seediq, Tsou, Saaroa, Kanakanavu, Thao, Tungho Saisiyat, and Nanwang Puyuma (Zeitoun, Teng, and Ferrell 2010: 868).
} 


\section{Gujing Lin}

Zeitoun and her colleagues note that the expressions for 20-90 (the multiples of ten) in Nanwang Puyuma involve the co-occurrence of the prefix maka-, a suffix, and a bound numeral which in certain cases are formally distinct from its free counterpart, as illustrated by drua " 2 " and maka-betra'an " 20 ". Such formal distinctions justify the co-existence of two sets of numerals. Their finding provides a critical insight to numerals in Nanwang Puyuma and other Formosan languages, even though there is no further description regarding the extent to which these distinctions may apply, nor is there discussion on the consequence they may have to the structuring principles of numeral systems in general. I will return to these two issues in the following section.

\section{Numerals in Tsou: When Multipliers Register the Exponents of the Numeral Base ${ }^{4}$}

My goal in the following paragraphs is two-fold: (1) to draw attention to the regularities emerging from the variations in Tsou numerals, especially when these variations are considered in broad context, and (2) to highlight their relevance to the structuring principles of numeral systems in general. I argue that the variations seen in Tsou numerals (for serial counting) stem from the collaboration of two sets of numerals, ${ }^{5}$ and the collaboration is related to the different exponentiations of the base 10 .

Like Nanwang Puyuma, Tsou also illustrates features of two sets of numerals: while one set of numerals designates number values under ten, the other set is employed for encoding the tens, as shown in (7) below.

\footnotetext{
4 The following research develops independently from Zeitoun and her colleagues' work. Tsou numerals first came to my attention when I was researching the morphophonological patterns of this language and intended to use the numerals, which form a well-defined subsystem, for testing different working hypotheses.

5 Zeitoun, Teng, and Ferrell (2010) also report the existence of two sets of numerals in Tsou.
} 


\section{(7) Tsou}

\begin{tabular}{|l|l|l|l|}
\hline coni & 1 & ma-ski & 10 \\
\hline yuso & 2 & m-pus-ku & 20 \\
\hline tuyu & 3 & m-tue-hu & 30 \\
\hline sipti & 4 & m-sipti- $h \dot{t}$ & 40 \\
\hline eimo & 5 & m-emo- $h \dot{t}$ & 50 \\
\hline nomi & 6 & m-onmi- $h \dot{t}$ & 60 \\
\hline pitu & 7 & m-pitvi- $h \dot{t}$ & 70 \\
\hline voyu & 8 & m-voevi-hi & 80 \\
\hline sio & 9 & m-sio- $h \dot{t}$ & 90 \\
\hline
\end{tabular}

At first glance, the expressions for the tens (i.e., $\left.x^{*} 10\right)$ in (7) appear to be constructed by associating the prefix $m(a)$ - and the suffix $-h i / h u$ with the corresponding numeral $\mathbf{x}$ in the leftmost column, thus giving rise to the impression that the two affixes $m(a)$ - and $-h i / h u / k u^{6}$ together mark the value of ten. A close look indicates that the formation of the tens is not immediately transparent. The opacity is manifest in the pairs of coni ' 1 ' vs. ma-ski '10' and yuso ' 2 ' vs. $m$-pus-ku '20'. There is nothing in the form of yuso ' 2 ' and pus (as of m-pus-ku ' 20 '), for instance, to indicate that the latter is directly derived from the former, nor is the presumptive $y \sim p$ alternation attested in this language (Tsuchida 1976, Ho 1976).

The assumption that the prefix $m a$ - and the suffix $-h i / h u / k u$ together designate the value of ten is also misleading. A comparison of the tens (shown in the third column from the left in (7)) with other numeral expressions in Tsou indicates that $m a$ - and $-h i / h u / k u$ can be dissociated from each other. Of the two affixes, only $m a$ - can be identified with the value of ten, the numeral base in Tsou. The suffix $-h i / h u / k u$ is found to contribute to the designation of values from 1 to 9 . In (8) below, the suffix $-h i / h u / k u$ combines with the roots pus and teu and denotes the number of times for which a particular action recurs. There is nothing in the meaning of m?e-pus.ku 'ask for something again' and mie-to-teu.hu 'ask for something for the third time' that may suggest the value of ten.

\footnotetext{
6 The three forms are allomorphs governed by vowel harmony and a phonological rule which turns $/ \mathrm{h} /$ to $/ \mathrm{k} /$ in Tsou. Morpho-phonological changes involved in Tsou numerals would be dealt with in another presentation/paper.
} 


\section{Gujing Lin}

(8a)

te=?o m?e-pus.ku to fue $=$ su?

AUX.IRR=1SG AF.ask.for-two(B) NTOP sweet.potato=2SG

"May I have sweet potatoes from you again?" (Lit.: "May I ask for your sweet potatoes for the second time?")

(8b)

te $=$ ?o m?e-to-teu.hu to fue $=$ su?

AUX.IRR=1SG AF.ask.for-REDU-three(B) NTOP sweet.potato=2SG

"May I have sweet potatoes from you for the third time?"

To distinguish pus.ku and its peer numerals from their counterparts in the leftmost column of (7), which do not take the $h u / h t / k u$ suffix, for this presentation I would refer to the latter as Set A numerals and the former as Set B numerals. The distinction between the two sets is found to extend to the construction of the hundreds and the thousands, as shown in (9) ${ }^{7}$ below. Set A numerals are used for constructing the hundreds together with the circumfix $s e$ ?-...-a 'hundred', as shown by se?-coni-a ' 100 '. Set B numerals are used for constructing the thousands, as shown by posi-po-pso.hi '2000.' During the formation, Set B numerals combine with the bound morpheme posi- 'thousand' and a partial reduplication process that copies the root-initial consonant followed by the fixed vowel $o$.

\footnotetext{
7 The alternation between pus.ku (as in m-pus.ku '20') and pso.hi (as in posi-po-pso.hi '2000'), together with other seemingly irregular alternations between corresponding forms within the same numeral set in (9), involves vowel deletion and vowel harmony. All the related morpho-phonological changes would be dealt with in another presentation/paper.
} 
Variations in Tsou Numeral Expressions

(9)

\begin{tabular}{|c|c|c|c|c|c|c|c|}
\hline \multicolumn{2}{|l|}{ Set $A^{8}$} & \multicolumn{2}{|l|}{ Set B } & \multicolumn{2}{|l|}{ Set A } & \multicolumn{2}{|l|}{ Set B } \\
\hline coni & 1 & \multirow[t]{2}{*}{$m a-s k i$} & \multirow[t]{2}{*}{10} & \multirow[t]{2}{*}{ ser-coni-a } & \multirow[t]{2}{*}{100} & \multirow[t]{2}{*}{ posifou } & \multirow[t]{2}{*}{1000} \\
\hline (veiau-cni) & $(n+1)$ & & & & & & \\
\hline yuso & 2 & \multirow{2}{*}{$m-p u s . k u$} & \multirow[t]{2}{*}{20} & \multirow[t]{2}{*}{ se?-eich-a } & \multirow[t]{2}{*}{200} & \multirow[t]{2}{*}{ posi-po-pso.hi } & \multirow[t]{2}{*}{2000} \\
\hline (veiau-eso) & $(n+2)$ & & & & & & \\
\hline tuyu & 3 & \multirow[t]{2}{*}{ m-tue.hu } & \multirow[t]{2}{*}{30} & \multirow[t]{2}{*}{ se?-tuev-a } & \multirow[t]{2}{*}{300} & \multirow[t]{2}{*}{ posi-to-tue.hu } & \multirow[t]{2}{*}{3000} \\
\hline (veiau-teu) & $(n+3)$ & & & & & & \\
\hline sipti & 4 & \multirow[t]{2}{*}{ m-sipti.hi } & \multirow[t]{2}{*}{40} & \multirow[t]{2}{*}{ se?-sipt-a } & \multirow[t]{2}{*}{400} & \multirow[t]{2}{*}{ posi-so-spot.hi } & \multirow[t]{2}{*}{4000} \\
\hline (veiau-spoti) & $(n+4)$ & & & & & & \\
\hline eimo & 5 & \multirow[t]{2}{*}{ m-emo.hi } & \multirow[t]{2}{*}{50} & \multirow[t]{2}{*}{$\operatorname{ser}-e i n v-a$} & \multirow[t]{2}{*}{500} & \multirow[t]{2}{*}{ posi-yo-emo.hi } & \multirow[t]{2}{*}{5000} \\
\hline (veiau-emo) & $(n+5)$ & & & & & & \\
\hline nomi & 6 & \multirow[t]{2}{*}{ m-onmi.hi } & \multirow[t]{2}{*}{60} & se?-nonv-a & 600 & posi-no-nmi.hi & 6000 \\
\hline (veiau-nmi) & $(n+6)$ & & & & & & \\
\hline pitu & 7 & m-pitvi.hi & 70 & se?-pitv-a & 700 & posi-po-ptu-hu & 7000 \\
\hline (veiau-ptu) & $(n+7)$ & & & & & & \\
\hline voyu & 8 & m-voevi.hi & 80 & se?-voev-a & 800 & posi-vo-veo.hi & 8000 \\
\hline (veiau-veo) & $(n+8)$ & & & & & & \\
\hline sio & 9 & $m$-sio.hi & 90 & $s e ?-s i-a$ & 900 & posi-so-sio.hi & 9000 \\
\hline (veiau-sio) & $(n+9)$ & & & & & & \\
\hline
\end{tabular}

As an interim summary, the construction of Tsou cardinals may appear to contain lots of irregular variations, as found in yuso '2,' m-pus.ku '20', and posi-po-pso.hi '2000.' When more data are considered, it occurs that the suffix $-h \mathrm{i} / h u / k u$ is unrelated to the designation of the base 10 (and its various exponentiations like 100 and 1000); instead, the suffix $-h \mathrm{i} / h u / k u$, together with the associated root, contributes to designating another set of number values from 1 9. The collaboration of these two sets of numerals leads to the variations in Tsou

${ }^{8}$ Set A numerals may surface as different allomorphs in different morpho-phonological environments, as found in coni ' 1 ' vs. veiau-cni 'plus 1' (as in maski veiau-cni '11; 10 plus 1') and yuso '2' vs. veiau-eso 'plus 2' (as in maski veiau-eso '12; 10 plus 2'). 


\section{Gujing Lin}

numerals: Set A numerals are employed for $1 \sim 9$ and the hundreds, whereas Set B numerals are for the decades and the thousands.

The collaboration of Set A and Set B numerals imposes significant consequences to our overall understanding of numeral systems, particularly how numerals are linguistically structured and where variations to the structuring principles may arise. As mentioned in Section 2, higher numerals, if relevant in the surveyed language, are typically constructed by the pattern in which some lower numeral $\mathbf{x}$ multiplied by a base $\mathbf{n}$ plus some other numeral $\mathbf{y}$ (Comrie 2008). Variations to the $\mathbf{x n}+\mathbf{y}$ formula typically arise when the surveyed language has more than one numeral base (see Section 2.1). In Tsou numeral system, however, the opacity in expressions arises from the alternating forms of the multiplier $\mathbf{x}$. To better illustrate the form alternation, I label the components of the $\mathbf{x n}+\mathbf{y}$ formula in subscript below.

$$
\begin{aligned}
& \text { posi-po-pso.hi ho m-pus.ku veiau-eso } \\
& \text { thousand-REDU-2(B) and ten-2(B) plus-2(A) } \\
& \text { “2022 (=10 } \left.{ }^{3} * 2(B)_{\mathbf{x}}+10^{1}{ }_{\mathbf{n}} * 2(\mathrm{~B})_{\mathbf{x}}+10^{0}{ }_{\mathbf{n}} 2(\mathrm{~A})_{\mathbf{x}}\right) \text { " }
\end{aligned}
$$

As illustrated by (10), the form of the multiplier $\mathbf{x}$ alternates between Set A numeral eso (the allomorph of yuso 'two', see (9)) and Set B numeral pso.hi (and its allomorph pus.ku). The alternation is found related to the exponentiation of the base 10: When the base 10 is raised to the power 0 and 2, the multiplier would be expressed by Set A numeral. When the base is raised to the power 1 and 3, the multiplier would be expressed by Set B numeral. Tsou numerals thus embody an unusual pattern in which the expression of the multiplier registers the different exponentiations of the base.

\section{Conclusion}

Even though the construction of Tsou numerals may appear opaque at first glance, a close inspection of the variations illustrates that two sets of lower cardinals collaborate to derive higher cardinals. The pattern of collaboration works in a way that Set A numerals mark number values under ten as well as the hundreds $\left(x^{*} 100\right)$, whereas Set B numerals are employed for the tens $\left(x^{*} 10\right)$ and the thousands $\left(x^{*} 1000\right)$. Tsou numerals thus embody an unusual pattern in which the expression of the multiplier registers the exponentiation of the base, and this pattern highlights a new source of variation which hopefully will bring in more inclusive understanding of numeral expressions in general. 
Variations in Tsou Numeral Expressions

\section{References}

Blust, Robert. 2009. The Austronesian Languages. Canberra: Pacific Linguistics.

Comrie, Bernard. 2008. Numeral Bases. In: Haspelmath, Martin \& Dryer, Matthew S. \& Gil, David \& Comrie, Bernard (eds.) The World Atlas of Language Structures Online. Munich: Max Planck Digital Library, chapter 131. Available online at http://wals.info/feature/131

Greenberg, Joseph H. 2000. Numeral. in G. Booij, C. Lehmann, J. Mugdan, in collaboration with W. Kesselheim, and Stavros Skopeteas (eds.) Morphology. An International Handbook on Inflection and Word Formation / Ein internationals Handbuch zur Flexion und Wortbildung. Vol 1. Berlin/New York: Mouton de Gruyter.

Heine, Bernd. 1997. Cognitive Foundation of Grammar. Oxford: OUP.

Ho, Dah-An. 1976. "Zou-yu-yin-yun (Tsou phonology)," Bulletin of the Institute of History and Philology 47, no. 2: 245-274.

Li, Paul J. 2006. Numerals in Formosan Languages. Oceanic Linguistics 45.1: 133-152.

Schmidt, P.W. 1926. Die Sprachfamilien und Sprachkreise der Erde. Heidelberg: Carl Winter's Universitatsbuchhandlung.

Tsuchida, Shigeru. 1976. Reconstruction of Proto-Tsouic phonology. Tokyo: Institute for the Study of Languages and Cultures of Asia and Africa, Tokyo Gaikokugo Daigaku.

Zeitoun, Elizabeth, Stacy F. Teng, and Raleigh Ferrell. 2010. Reconstruction of ' 2 ' in PAN and Related Issues. Language and Linguistics 11:4:853-884.

Gujing Lin

No. 67, Jieren St., Hualien

97074, Taiwan, R.O.C

paicxeevi@mail.tcu.edu.tw 